\title{
Análise sobre As novas formas de controle no Estudo da Ideologia da Sociedade Industrial de Herbert Marcuse
}

\author{
Analysis on The new forms of control in the Study of the Ideology of the \\ Industrial Society of Herbert Marcuse
}

\author{
THIAGO ROQUE DE SOUZA ${ }^{1}$
}

\begin{abstract}
Resumo: Este trabalho consiste na realização de algumas considerações referentes à análise do Capítulo o1 - As novas formas de controle, da obra $O$ homem unidimensional: Estudo da Ideologia da sociedade industrial, do filósofo alemão Herbert Marcuse. Capítulo no qual o teórico crítico aborda questões como a extinção da individualidade na mecanização de performances socialmente necessárias, ou seja, os ditos "empreendimentos individuais", onde se inserem os indivíduos na regulação da "livre" competição entre sujeitos econômicos desigualmente equiparados, ordenados pelo progresso técnico, envolvidos por uma coordenação política e intelectual que pode ser compreendida como uma evolução lamentável, fruto da dinâmica da civilização industrial avançada, organizada e dirigida agora pelo aparato produtivo que age como forma de controle. Sendo estas formas obsoletas superimpostas na unidimensionalidade social dos indivíduos.
\end{abstract}

Palavras-chave: Mecanização. Civilização Industrial. Formas de controle.

Abstract: This work consists in the realization of some considerations referring to Chapter o1 - The new forms of control, from the book One-Dimensional man: Studies in the Ideology of the Advenced Industrial Society, of the german philosopher Herbert Marcuse. Chapter in which the critical theorist addresses issues such as the extinction of individuality in the mechanization of socially necessary performances, that is, the so-called "individual enterprises", where individuals are inserted in the regulation of "free" competition among unequally equated economic subjects ordered by Technical progress, involved in a political and intellectual coordination that can be understood as an unfortunate development, fruit of the dynamics of advanced industrial civilization, organized and now directed by the productive apparatus that acts as a form of control. These obsolete forms are superimposed on the social unidimensionality of individuals.

Keywords: Mechanization. Industrial Society. Forms of Control.

1 Supressão da individualidade e a perca da razão, dos direitos e liberdades, por meio da institucionalização e mecanização dos sujeitos na civilização industrial avançada

Herbert Marcuse (1898 - 1979) abordou em sua obra O homem unidimensional: Estudo da Ideologia da sociedade industrial ${ }^{2}$, questões como a extinção da individualidade no processo de mecanização de performances socialmente necessárias, compreendidas como "empreendimentos individuais", que inserem os indivíduos na regulação da livre competição entre sujeitos economicamente desiguais, equiparados e ordenados pelo progresso técnico, culminando na supressão

'Acadêmico do Mestrado em Filosofia pela Universidade Estadual do Ceará - UECE. E-mail: prof.thiagoroque@gmail.com.

${ }^{2}$ One-dimensional man. Studies in the ideology of advanced industrial society - 1964.

Diaphonía, e-ISSN 2446-7413, v. 3, n. II, 2017 
da individualidade e na perca da razão dos direitos e liberdades, por meio da instrumentalização da razão e como uma nova forma de controle na civilização industrial avançada, pois, ao transcorrer pela ideia de Institucionalização de Direitos e Liberdades, o filósofo percebe que os direitos e liberdades perdem sua razão e seu conteúdo tradicional, haja visto que uma vez institucionalizados, o destino da sociedade da qual eles tinham se tornado uma parte integral como fatores vitais, deixam de existir na nova forma de comportamento assessorado pelos aparatos produtivos da sociedade industrial, que servem como novas formas de controles.

\subsection{A não-liberdade confortável, racional e democrática, que se apresenta como um progresso técnico na civilização industrial avançada, através da mecanização de performances socialmente necessárias}

Na civilização industrial avançada fica perceptível a não-liberdade que pode ser compreendida como confortável, muito agradável, racional e aparentemente democrática. Esta poderia ser mais do que o resultado da ação de eliminar a individualidade na mecanização de performances socialmente necessárias, pois a concentração de empreendimentos individuais em corporações compreendidas como mais eficientes, ou seja, mais produtivas, visto que nesse contexto, eficiência se equipara à máxima capacidade de produção dos modelos capitalistas modernos, que acabam regulando a livre competição entre os sujeitos, que se colocam como desigualmente equiparados, iludidos por uma falsa ideia de liberdade, seja econômica como individual, desconsiderando o homem como sujeito em si, segundo Marcuse.

Uma não-liberdade confortável, muito agradável, racional e democrática prevalece na civilização industrial avançada, um sinal do progresso técnico. Na verdade, o que poderia ser mais racional que a supressão da individualidade na mecanização de performances socialmente necessárias, mas penosas; que a concentração de empreendimentos individuais em corporações mais eficientes, mais produtivas; que a regulação da livre competição entre sujeitos econômicos desigualmente equiparados; que a restrição de prerrogativas e soberanias nacionais que impedem a organização internacional dos recursos? Que este ordenamento tecnológico envolva também uma coordenação política e intelectual pode ser uma evolução lamentável mais ainda promissora (MARCUSE, 2015, p.41).

A concentração de empreendimentos individuais em corporações mais eficientes e produtivas que regulam a livre competição entre os sujeitos econômicos desigualmente equiparados, se mostra como resultado da supressão (eliminação ou extinção) da individualidade na mecanização de performances socialmente necessárias. Sendo assim, a própria restrição de prerrogativas e soberanias nacionais que podem impedir a ordenação internacional de recursos, envolvendo este 
ordenamento tecnológico, a uma coordenação política e intelectual, pode ser entendida como uma possível evolução lamentável, porém, muito promissora.

Torna-se claro que o ordenamento que advém do desenvolvimento tecnológico, sendo o próprio promovido e gerenciado pela sociedade industrial, envolve uma espécie de coordenação política e ao mesmo tempo intelectual, que se estabelece mais como uma evolução deplorável e lamentável, do que necessariamente racional ou promissora aos homens. Esse é o resultado da eliminação da individualidade dentro das performances de mecanização dos sujeitos, pois, esta agora, passa a ser visto apenas como sujeitos subordinados a lógica da produção (sujeitos produtivos), prevalecendo sua extinção como fator vital, em decorrência ou em provimento da mecanização dos aspectos individuais e dos seus empreendimentos que prevalecem na sociedade industrial avançada.

A não - liberdade confortável, racional e democrática, que se apresenta como um progresso técnico na civilização industrial avançada, acontece no momento em que a individualidade é suprimida pela mecanização de performances socialmente necessárias. Influenciando diretamente no que se refere aos direitos e liberdades nos panoramas da sociedade industrial, haja visto que os direitos e liberdades, acabam perdendo sua razão em seu conteúdo tradicional, se rendendo ao estágio dito "superior", do modelo de sociedade industrial avançada.

\subsection{Os direitos e liberdades que se rendem ao estágio superior na prospectiva da sociedade industrial avançada, na perda de sua razão e de seu conteúdo tradicional}

Os direitos e liberdades na conjuntura da sociedade industrial, inicialmente eram compreendidos como fatores vitais nas origens e nos estágios da sociedade industrial. Porém, esses direitos e liberdades, acabam se entregando ao estágio superior dessa mesma sociedade. Os direitos e liberdades perdem sua razão e seu conteúdo tradicional, pois a liberdade de pensamento, consciência e palavra, como também a livre iniciativa que essa liberdade promovia e até mesmo protegia, eram percebidas como ideias essencialmente críticas, designadas para substituir uma cultura material e intelectual obsoleta por mais uma produtiva, visto de forma equivocada como racional dentro desse viés. Segundo Marcuse:

Os direitos e liberdades em que eram os fatores vitais na origens e nos estágios iniciais da sociedade industrial se renderam ao estágio superior dessa mesma sociedade; esses direitos e liberdades estão perdendo sua razão e seu conteúdo tradicionais. Liberdade de pensamento, palavra e consciência é - assim como a livre iniciativa, que ela promoveu e protegeu - essencialmente ideias críticas, designadas para substituir uma cultura material e intelectual obsoleta por uma mais produtiva e racional (MARCUSE, 2015, p. 41). 
Esse processo acaba institucionalizando os direitos e liberdades que deveriam ser algo que pertencesse genuinamente aos indivíduos. Porém, uma vez institucionalizados esses direitos e liberdades, no contexto abordado, torna-se o destino dessa sociedade, sem condições de libertar-se das necessidades criadas pela estrutura da sociedade industrial, que podem ser compreendidas por meio da regulação da livre competição entre os sujeitos econômicos desigualmente equiparados. Contribuindo para a perda dos reais valores vitais dos direitos e liberdades dos indivíduos.

No momento que esses direitos e liberdades são institucionalizados, eles passam a compartilhar o destino, ou o desejo, da sociedade da qual se tornam parte integral. Entretanto, na medida que libertar-se da substância concreta de toda liberdade, torna-se uma possibilidade possível de pertencerem a um estado de baixa produtividade, perdendo seu conteúdo original (independência de pensamento, autonomia e o direito de oposição política). As liberdades que pertencem a esse estado de baixa produtividade, priva funções essencialmente crítica em uma sociedade que mais parece capaz de satisfazer as necessidades dos indivíduos por meio da forma como se organiza.

Essa organização, retira conteúdos originais como: o direito de oposição política, autonomia e as formas de pensamentos independentes, pois a sociedade industrial exige a aceitação de seus princípios e instituições que buscam reduzir a promoção e discussão de alternativas políticas dentro do status quo, porque acaba não fazendo tanta diferença se a crescente satisfação das necessidades é realizada por um sistema autoritário ou não. Os direitos e liberdades perdem seus direitos de oposição política e sua autonomia na inserção do aparato produtivo nesse modelo de sociedade.

1.3 A institucionalização dos direitos e liberdades que se encontram em campo de baixa produtividade ao perder sua autonomia e os direitos de oposição política no contexto de inserção do aparato produtivo

A institucionalização dos direitos e liberdades compartilham o destino da sociedade da qual eles tinham se tornado uma parte integral, posto que, eram fatores vitais nas origens da sociedade industrial. Nesse sentido, tanto os direitos como as liberdades perdem sua razão em seu conteúdo tradicional, tornando-se sua cultura material e intelectual como uma forma de cultura arcaica (obsoleta), que acaba sendo substituída por uma forma produtiva "racional", dentro do caráter da civilização industrial avançada.

[...] Uma vez institucionalizados, esses direitos e liberdades compartilham o destino da sociedade da qual tinham se tornado uma parte integral. A realização cancela as premissas. 
À medida que se libertar-se da necessidade, que é a substância concreta de toda liberdade, está se tornando uma possibilidade real, as liberdades que pertencem a um estado de baixa produtividade estão perdendo seu conteúdo original. Independência de pensamento, autonomia e o direito de oposição política estão sendo privados de sua função essencialmente crítica em uma sociedade que parece crescentemente capaz de satisfazer as necessidades dos indivíduos por meio da forma como está organizada (MARCUSE, 2015, p.41-42).

As liberdades que se encontram em campo de baixa produtividade, acabam perdendo sua "singularidade", pois está sendo privado a independência de pensamento, autonomia e o direito de oposição política frente as máximas impostas por esse paradigma de sociedade, extinguindo sua função essencialmente crítica em uma forma que mais parece ser crescentemente capaz de satisfazer as necessidades dos indivíduos por meio da forma como está sendo organizado a sociedade industrial. Sendo assim, a cultura material e intelectual se tornam obsoletas no encadeamento da institucionalização dos direitos e liberdades na sociedade industrial.

O encadeamento da institucionalização dos direitos e liberdades que tornam a cultura material e intelectual em formas obsoletas, acabam substituindo esses direitos e liberdades em uma forma produtiva "racional" que contribui para o desenvolvimento do aparato produtivo e das formas de controles sociais, bem típicas da conduta vigente nesse corpo social que é a sociedade industrial avançada. Diante de um crescente padrão de vida socialmente inútil, que acarreta desvantagens econômicas e políticas concretas que ameaçam o bom funcionamento do todo.

Enquanto as necessidades da vida estiverem inseridas em uma crescente forma de padrão de vida, assessorada pelo aparato produtivo, parece não haver razão para que a produção e a distribuição de bens e serviços prosseguissem por meio da concorrência competitiva entre as liberdades individuais. Pois, a livre iniciativa não foi, desde o início, uma vantagem enquanto liberdade para trabalhar ou morrer de fome, ou seja, a labuta, o medo e a insegurança para uma grande maioria da população.

\section{O aparato produtivo que caracterizam as formas predominantes de controle social na civilização industrial}

2.1 A livre iniciativa enquanto "liberdade" (A falsa liberdade), que se vincula ao aparato produtivo, para satisfação de necessidades vitais na sociedade industrial

A liberdade enquanto significar labuta, insegurança e medo para uma grande parcela da população, ela sempre vai se apresentar como uma desvantagem, pois, o indivíduo é forçado a ser bem-sucedido no mercado, como um sujeito economicamente livre. Porém, caso o indivíduo não fosse mais forçado a ser bemsucedido no mercado, o desaparecimento desse modelo de liberdade seria uma das 
maiores realizações da civilização. Nesse formato de sociedade, um crescente padrão de vida parece não ter muito discernimento se o crescimento dos mecanismos são para satisfazer suas próprias necessidades.

\begin{abstract}
A livre iniciativa não foi, desde o início, uma vantagem. Enquanto liberdade para trabalhar ou morrer de fome, isso significou labuta, insegurança e medo para uma grande maioria da população. Se o indivíduo já não fosse mais forçado a ser bem-sucedido no mercado, como um sujeito economicamente livre, o desaparecimento desse tipo de liberdade seria uma das maiores realizações da civilização. Os processos tecnológicos de automação e estandardização podem liberar energia individual para um reino ainda desconhecido de liberdade, situado para além da necessidade (MARCUSE, 2015, p.42).
\end{abstract}

O crescimento dos mecanismos do aparato produtivo e suas exigências econômicas e políticas realizada por um sistema autoritário ou por uma conformidade parece ser também socialmente inútil, acarretando desvantagens econômicas e políticas concretas, que ameaçam a funcionalidade do todo, culminada, por meio da concorrência competitiva entre liberdades individuais, agora fortalecidas e gerenciadas por uma mera ilusão chamada de "livre iniciativa", porque o aparato produtivo impõe suas exigências econômicas e políticas de defesa e expansão sobre o tempo trabalhado e o tempo livre.

Quando comentamos sobre a concorrência competitiva entre liberdades individuais, consequentemente, temos que pontuar sobre a questão da livre iniciativa, esta que não foi desde o início uma vantagem para os indivíduos. Pelo contrário, tudo isso passou a fortalecer uma forma árdua de trabalho, pois o indivíduo acaba entrando em uma situação que ele possui uma falsa liberdade para trabalhar ou em ter que escolher passar fome. Essa insegurança traz medo para boa parte das pessoas, pois, esse comportamento acaba forçando os indivíduos a buscarem se inserir de qualquer forma e a todo custo no mercado, para se tornarem indivíduos "bem-sucedidos" e sujeitos economicamente livres.

Vale lembrar que, a livre inciativa não se coloca necessariamente como uma vantagem aos indivíduos em nenhum momento, nesse sentido, podemos pontuar também que a ideia de "liberdade interior" tem aqui sua realidade, que se designa no espaço privado no qual o homem se torna e permanece "ele mesmo", dentro da perspectiva do aparato produtivo, para satisfação de necessidades vitais das formas predominantes de controles sociais, bastante pertinentes na cultura industrial, resultando no desaparecimento da própria liberdade em si, na qual o indivíduo é livre para exercer a autonomia sobre uma vida que seria propriamente sua.

\title{
2.2 O sujeito economicamente livre que impede a autonomia individual, quando a liberdade desaparece no advento do aparato produtivo
}


O sujeito economicamente livre e bem sucedido na sociedade industrial pode ter aparentemente "tudo", menos sua liberdade. Pois, o objetivo nessa dinâmica social seria exatamente possibilitar o desaparecimento de qualquer forma real de liberdade, ou seja, liberdade impossibilitada, se tornando, um fato ou uma realização dessa civilização, que conta também com os processos tecnológicos de automação e "estandartização" que liberam forças individuais para um "reino" desconhecido de liberdade, se situando para além de suas necessidades falaciosas nas perspectivas industriais.

A própria estrutura da existência humana seria alterada; o indivíduo seria liberado do mundo do trabalho que impõe a ele necessidades e possibilidades que lhe são estranhas. O indivíduo seria livre para exercer a autonomia sobre uma vida que seria propriamente sua. Se o aparato produtivo pode ser organizado e dirigido para a satisfação das necessidades vitais, seu controle pode muito bem ser centralizado; tal controle não impediria a autonomia individual, mas a tornaria possível (MARCUSE, 2015, p.42).

Marcuse observa que a própria estrutura da existência humana seria alterada. $\mathrm{O}$ indivíduo seria isento do mundo do trabalho que condiciona a ele "necessidades" e possibilidades estranhas, para exercer sua autonomia. $\mathrm{O}$ indivíduo deveria ser livre e sua vida tinha que pertencer a si mesmo, assim o indivíduo seria livre para exercer a autonomia sobre uma vida que seria propriamente sua, evitando ficar submisso a qualquer aparato que alterasse a estrutura da existência humana, como acontece no advento do aparato produtivo.

Se o aparato produtivo pode ser organizado e dirigido para a satisfação das necessidades vitais de seus interesses, seu controle pode muito bem ser centralizado, porém, esse controle não era para impedir a autonomia individual, mas deveria tonárla possível. Entretanto, o que acontece é exatamente o contrário, porque acaba sendo uma meta contida nas capacidades da civilização industrial avançada, o "fim" da racionalidade tecnológica.

A racionalidade tecnológica na realidade, serve ao aparato produtivo que impõe suas exigências políticas e econômicas sobre a cultura material e intelectual, influenciando na relação do tempo de trabalho e tempo livre. Dessa forma essa racionalidade se organiza tendo como base técnico-econômica de manipulação das necessidades e interesses, as formas de controles sociais, que se manifestam também por meio do aparato produtivo da sociedade industrial.

\subsection{A manifestação das formas de controles sociais, que por meio do aparato produtivo, nos direcionam a uma estrutura de pensamento unidimensional}

Sabendo que o aparato produtivo pode ser organizado para satisfazer as necessidades vitais, seu controle pode muito bem ser centralizado; tal controle não impediria a autonomia individual, mas a tornaria possível. Porém, o aparato impõe 
suas exigências econômicas e políticas de defesa e expansão sobre o tempo de trabalho e o tempo livre, sobre a cultura material e intelectual. Isso deve-se a forma em que este se organiza, pois, a sociedade industrial contemporânea tende a ser totalitária e não apenas só em uma coordenação política terrorista da sociedade, mas de uma coordenação política técnico-econômica, de um sistema específico de produção e distribuição compatível com o "pluralismo" e aos "poderes compensatórios". Como percebemos na seguinte passagem:

\begin{abstract}
Esta é uma meta contida nas capacidades da civilização industrial avançada, o "fim" da racionalidade tecnológica. Entretanto, na realidade atual, opera a tendência oposta: o aparato impõe suas exigências econômicas e políticas de defesa e expansão sobre o tempo de trabalho e o termo livre, sobre a cultura material e intelectual. Em virtude da maneira que ela organizou sua base tecnológica, a sociedade industrial contemporânea tende a ser totalitária. Pois "totalitária" não é apenas uma coordenação política terrorista da sociedade, mas também uma coordenação técnico-econômica não terrorista que opera através de manipulação das necessidades por interesses escusos (MARCUSE, 2015, p.42).
\end{abstract}

Quando pontuamos aqui que a sociedade industrial tende a ser totalitária, vale lembrar que o termo "totalitário" se apresenta no sentido de uma coordenação técnico-econômica e não terrorista que opera através da manipulação das necessidades (um sistema específico de produção - os poderes compensatórios) por interesses escusos, ou seja, que pode gerar algum tipo de desconfiança. A máquina aqui se apresenta como o mais efetivo instrumento político, pois, a dominação política se afirma por meio de seu poder político, sobre os processos mecânicos em qualquer sociedade, sua organização básica se mostra na organização técnica do aparato e do processo maquinal.

Marcuse comenta que o governo das sociedades industriais avançadas em desenvolvimento, só podem se manter e se garantir quando contém êxito em mobilizar, organizar e explorar a produtividade técnica, científica e mecânica, disponíveis na civilização industrial. Em linhas gerais, o aparato produtivo está associado diretamente às formas de controle, que é organizado e dirigido para as satisfações de suas necessidades vitais, ou seja, mantendo o controle centralizado (controle $\mathrm{x}$ autonomia / possível $\mathrm{x}$ impossível), pois, essa produtividade mobiliza a civilização industrial por inteira.

Portanto, as formas predominantes de controles sociais por meio do instrumento prolífico (o poder da máquina enquanto produtivo), são tecnológicas em um novo sentido: da estrutura técnica e da eficácia do aparato produtivo busca condicionar os indivíduos à divisão social do trabalho pré-determinado e nos padrões desse modelo social, na medida em que essa relação (do mundo do trabalho), seja concebida como uma máquina que mecaniza a base potencial de uma nova liberdade 
para os indivíduos, outrossim, o poder da máquina seria o próprio poder do homem projetado e armazenado nos padrões desse modelo social, que nos direcionam a um pensamento unidimensional por meio do aparato produtivo e suas formas de controle social.

\section{O pensamento e o comportamento unidimensional que influencia na forma de controle dos indivíduos, na perspectiva da sociedade industrial como estabelecedora de relações específicas de produção (processo maquinal)}

3.1 Os poderes compensatórios que se apresentam como forma de sistema específico na sociedade industrial, cuja organização básica se encontra em seu processo maquinal

No pensamento e comportamento unidimensional, o poder da máquina se apresenta como um poder do homem armazenado e projetado. Pois, o fato brutal de que o poder físico da máquina transcende ao que pertence ao indivíduo, de qualquer grupo particular de indivíduos, que fazem da máquina o mais efetivo instrumento político em qualquer estrutura social em que consiste sua sustentação básica, o processo maquinal.

[...] O fator brutal de que o poder físico (somente físico?) da máquina ultrapassa aquele do indivíduo, e de qualquer grupo particular de indivíduos, faz da máquina o mais eficiente instrumento político em qualquer sociedade cuja organização básica seja aquela do processo maquinal. Mas a tendência política pode ser revertida; essencialmente, o poder da máquina é apenas o poder do homem armazenado e projetado. À medida que o mundo do trabalho é concebido como uma máquina e mecanizado dessa forma ele se torna a base potencial de uma nova liberdade para o homem (MARCUSE, 2015, p.43, grifo do autor).

Marcuse observa que a civilização industrial contemporânea demonstra que alcançou o estágio no qual "a livre sociedade" não pode mais ser adequadamente definida nos termos tradicionais das liberdades econômicas, intelectuais e políticas, porque elas são demasiadamente significativas para serem abordadas dentro de formas tradicionais. Pois, essas sociedades se tornaram insignificantes, mas porque elas são exatamente demasiadamente significativas e confinadas dentro de formas tradicionais (por tais motivos, percebe-se de forma necessária, novos procedimentos de realizações, que correspondam às novas capacidades da sociedade).

De forma semelhante, na ideia da liberdade intelectual, quando se fala no sistema específico de produção, notamos que há uma estirpe que se mostra como uma restauração do pensamento particular (a restauração do pensamento individual. p.43) que passa a ser absorvido pelas formas de doutrinações que buscam representar o próprio fim da "opinião pública”, junto aos seus autores do vigor das forças que impedem sua realização. A máquina e todo seu aparato, se unifica, buscando sentido 
"uno" nas relações específicas de produção, visto que a máquina e por consequência, as formas específicas de produção na civilização industrial, criam soluções para possíveis problemas ou necessidades que as mesmas criaram.

Essa é a organização básica do processo maquinal, que busca tornar impossível muitas vezes, a superação de qualquer caráter utópico das forças produtivas e de controle. Prevalecendo os poderes compensatórios, sendo observado na "inculcação" de necessidades materiais e intelectuais que se perenizam em preservar e gerar as formas obsoletas de luta pela existência no moldes dessa estrutura. Devido a essas questões, os poderes compensatórios se apresenta como forma de sistema específico na sociedade industrial, cuja sua organização se encontra no processo maquinal.

\subsection{As formas obsoletas de existência e as necessidades superimpostas aos indivíduos na unidimensionalidade social}

As formas obsoletas de existência intercalam na intensidade e satisfação das "necessidades" humanas. A possibilidade de fazer algo ou de se deixar fazê-lo, de desfrutar ou de destruir, de possuir ou rejeitar algo, é tomada como uma "necessidade" (Visto que em última análise, a questão sobre as quais necessidades são verdadeiras ou falsas deve ser respondida pelos próprios indivíduos).

[...] A mais efetiva e duradoura das guerras contra a libertação é inculcação de necessidades materiais e intelectuais que perpetuam formas obsoletas de luta pela existência. [...] Nós podemos distinguir entre necessidades verdadeiras e falsas. "Falsas" são aquelas que são superimpostas ao indivíduo por interesses sociais particulares para reprimi-lo: as necessidades que perpetuam a labuta, a agressividade, a miséria e a injustiça. Sua satisfação pode ser mais gratificante para o indivíduo, mas essa felicidade não é uma condição que deva ser mantida e protegida se ela serve para impedir o desenvolvimento da capacidade (sua própria e dos outros) de reconhecer a enfermidade de todo e de perceber as chances de curá-la (MARCUSE, 2015, p. 44).

Entretanto, isso deve depender da potencialidade das necessidades de poderem ou não serem vistas como algo desejável e indispensável para as instituições que a sociedade industrial regimentam. De certo modo, elas exigem como forma de desenvolvimento, este que por sua vez, se torna repressivo. Na verdade, se conduzindo por suas próprias demandas e seus padrões críticos, dominantes de uma configuração unidimensional da sociedade.

Quando abordamos as formas obsoletas de existência e as necessidades superimpostas aos indivíduos na unidimensionalidade social, consequentemente temos a obrigação de levantarmos problemáticas no que se refere as necessidades ditas verdadeiras e falsas. De imediato, nós podemos entender que as necessidades falsas compreendem aquelas que são superimpostas aos indivíduos por interesses particulares para reprimi-lo: as necessidades que perpetuam a labuta (o trabalho 
árduo e penoso). A agressividade, a injustiça e por consequência, o estado deplorável onde a felicidade não se condiz ao homem, pois essa necessidade impede o desenvolvimento da capacidade de reconhecer a debilidade do todo e de reconhecer as chances de repará-las, revertendo toda situação superimpostas agregadas aos mecanismos de controles sociais e industriais.

As necessidades vitais já poderiam ser recompostas devido ao estágio em que o desenvolvimento técnico já alcançou, mas a sociedade industrial por meio das suas formas obsoletas, acaba nos guiando à outros interesses, outras formas de satisfação que podem ser entendidas como um pré-requisito para a realização de todas as necessidades pré-determinadas, tanto das não-sublimadas quanto das sublimadas, pois, para toda consciência e toda experiência que não aceitem o interesse social predominante como a suprema lei do pensamento e comportamento unidimensional.

Para Marcuse, a "verdade" e a "falsidade" das necessidades designam condições objetivas no sentido de que a satisfação universal das imprescindibilidades vitais se encontrem de forma natural entre os indivíduos inseridos neste contexto. Porém, o alívio progressivo do trabalho árduo e do estado deplorável, são critérios válidos universalmente porque os controles sociais estão ligados diretamente a essas questões e exigem a necessidade "irresistível" da produção e consumo na civilização industrial, levando-nos ao processo que Marcuse denomina de imbecilização ${ }^{3}$, ficando a cargo de ser respondida pelos próprios indivíduos se essas necessidades são obrigatoriamente verdadeiras ou falsas.

\section{3 $\mathrm{O}$ impacto do progresso que transforma a razão em submissão aos fatos da vida e sua contradição como elemento irracional em sua racionalidade na sociedade industrial}

Na sociedade industrial, a liberdade se desvincula do seu real sentido a uma falsa ideia, se apresentando como instrumento de dominação (forma de controle), pelo fato de ser observado que quanto mais racional, produtiva, técnica e total se torna a administração repressiva da sociedade, mas inimagináveis se tornam os meios e os modos pelos quais os indivíduos administrados poderiam quebrar sua servidão e tomar sua libertação em suas próprias mãos.

As mais avançadas áreas da sociedade industrial exibem completamente estes dois traços: uma tendência para a consumação da racionalidade tecnológica e os esforços intensivos para conter essa tendência dentro das instituições estabelecidas. Eis aí a contradição interna dessa civilização; o elementos irracional em sua

\footnotetext{
3"Os controles sociais exigem a necessidade irresistível de produção e consumo de supérfluos; a necessidade de trabalho imbecilizante onde isso não é mais necessário; a necessidade de modos de relaxamento que aliviam e prolongam essa imbecilização; a necessidade de manter liberdades enganosas como a livre concorrência com preços administrados, uma imprensa livre que se autocensura, a livre escolha entre marcas idênticas e acessórios inúteis" (MARCUSE 2015, p. 46).
} 
racionalidade. É a evidência de suas realizações. A sociedade industrial, que faz da tecnologia e da ciência suas propriedades, está organizada para a dominação cada vez mais efetiva do homem e da natureza, para a utilização cada vez mais efetiva de seus recursos (MARCUSE, 2015, p.54).

Marcuse comenta que o traço símbolo da sociedade industrial avançada seria sua capacidade efetiva de sufocar aquelas necessidades que demandam libertação. Esta seria de algo tolerável, confortável e ao mesmo tempo gratificante, que sustenta e absorve o poder destrutivo e a função repressiva da sociedade confluente. Aqui, de forma notória, retornamos ao ponto no qual trabalhamos sobre os controles sociais, visto que estes, criam irresistíveis necessidades de consumo e produção aos indivíduos, mesmo que essas fascinantes necessidades sejam supérfluas.

As necessidades irresistíveis de consumo e produção, cria uma "indispensabilidade" de trabalho imbecilizante. Porém, mantém liberdades enganosas como a livre concorrência, a livre escolha e a livre imprensa, esta última que ironicamente até se autocensura ao criar necessidades inúteis sobre a forma de dominação da sociedade industrial, a livre escolha (no contexto da forma de dominação da sociedade industrial) não significa liberdade e progresso, mas uma necessidade superimpostas que não estabelece, nem possibilita a construção de uma autonomia. Sendo exposta claramente apenas como eficácias das formas de controles sociais e seus impactos na submissão aos fatos da vida na capacidade dinâmica de produzir e reconhecer o sistema e seu poder repressivo.

É importante ressaltarmos o impacto do progresso que transforma a "razão" em submissão aos fatos da vida e à capacidade dinâmica de produzir mais. Nesse sentido, o filósofo atribuí o conceito de alienação como algo questionável no momento em que os indivíduos se identificam com a existência que lhes é imposta e acabam "enxergando" nela seu próprio desenvolvimento de satisfação e identificação, nunca percebendo sua existência alienada, levando-os a "falsa consciência" de sua racionalidade. Essa razão prática e teórica se percebe na sociedade avançada que converte o progresso científico e técnico em um instrumento de dominação, que pode ser compreendido como o "Progresso"4.

Este progresso não é um termo pacífico ou isolado, pelo contrário, ele sai da inércia para fins específicos que são definidos pelas possibilidades de melhoria da condição humana. Nesse momento, a sociedade industrial busca se aproximar do estágio em que o progresso contínuo exigiria a subversão radical da direção da organização preeminentes do progresso, pois, as mais avançadas áreas da sociedade industrial, se exibem integralmente por dois traços, sendo a primeira uma tendência

\footnotetext{
4“Progresso" não é um termo neutro; ele se move para fins específicos e esses fins são definidos pelas possibilidades de melhoria da condição humana. A sociedade industrial avançada está se aproximando do estágio em que o progresso contínuo exigiria a subversão radical da direção e da organização predominantes do progresso. (MARCUSE 2015, p.53).
} 
de consumação da racionalidade tecnológica e a segunda os esforços intensivos para conter essa tendência dentro das instituições estabelecidas.

A sociedade industrial avançada é organizada pela dominação efetiva do homem, para utilizar cada vez mais e de forma efetiva seus recursos. Isso mostra que ela além de ser contraditória, ela se apresenta de forma irracional. O sucesso desses esforços, abrem novas dimensões para a realização humana, porque, toda liberdade depende da conquista de necessidades de outra natureza segundo Marcuse.

A realização da liberdade depende das técnicas dessas conquistas, pois, quando esse ponto for "conquistado", ou seja, o rompimento com a disfarçada ideia de liberdade superimposta pela sociedade estabelecida, que por meio de seu aparato produtivo e de suas formas de controle, controla a indústria avançada, os indivíduos deixariam de agir conforme o pensamento unidimensional, contrariando a lógica do universo estabelecido do discurso e da ação.

Portanto, compreender que os aparatos produtivos da realidade estabelecida domina a sociedade industrial avançada, as ações e as necessidades dos indivíduos inseridos em tal contexto, está sendo assessorada por uma racionalidade técnica que se mantém no estado de defesa desse universo de dominação, seria um dos primeiros passos para superação ${ }^{5}$ do comportamento unidimensional, haja visto que, a sociedade industrial avançada é dominada pelo aparato lógico-produtivo do capitalismo e gerenciada por uma razão instrumentalizada e operacionalizada pelos seus agentes de controle.

\section{Conclusão}

Marcuse em sua obra, descreve práticas que apresentam as estruturas preexistentes, as normas e os comportamentos, em contraste com a manifestação estrutural, multidimensional que focaliza, possibilidades que transcendem o estado de coisas estabelecidas na sociedade industrial. Ao analisar as formas de controles dentro da perspectiva da sociedade industrial avançada, podemos compreender como se estabelece a relação: indivíduo x sociedade. Essa relação nos oportuniza buscar compreender a racionalidade individual em contraposição a irracionalidade e a dominação do indivíduo dentro do contexto desse modelo de sociedade.

A ausência de liberdade que prevalece na civilização industrial avançada é o que gerencia as novas formas de controle, institucionalizando direitos e liberdades na perda de seu sentido (ou razão) em seu âmbito, sendo substituída por uma forma produtiva racional dentro do contexto dessa sociedade que se apresenta mais como irracional (a "racionalidade" industrial) do que racional, muitas vezes passando

5Pois tal realidade estabelecida não deixa de se mostrar como um modelo de sociedade contraditória em seu elemento "racional", que é redefinido pela racionalidade instrumentalizada pelos aparatos produtivos e pelos poderes compensatórios. 
despercebida pelos indivíduos ao acreditarem em uma falaciosa ideia de liberdade, ou seja, a de produção e consumo, como necessidades vitais.

A livre iniciativa aqui não se põe como vantagem, mas como algo extremamente associado ao aparato produtivo que se organiza e converge para atender as necessidades vitais, para a dominação de seu controle. Impedindo qualquer autonomia individual, pois a sociedade industrial tende a ser totalitária no sentindo técnico-econômico, favorecendo um sistema específico de produção compreendido como: poderes compensatórios, pois o aparato impõe suas exigências econômicas e políticas de defesa e expansão sobre o tempo de trabalho e o tempo livre sobre a cultura material e imaterial. Isso em virtude da maneira que se organiza sua base tecnológica.

As formas de controles sociais se subdividem nas necessidades irresistíveis de produção e consumo que culmina segundo o filósofo no processo de imbecilização. A falsa ideia de "liberdade" como instrumento de dominação, tende ir contra a "pacificação da existência" (a crescente produtividade), haja visto que o sistema específico de produção, poderes compensatórios, guia-nos enquanto indivíduos inseridos no contexto da sociedade industrial, às formas obsoletas de existência e às necessidades "verdadeiras" e "falsas" que de fato, são superimpostas pela sociedade industrial avançada.

Marcuse percebe divergências entre as necessidades "verdadeiras" e "falsas", sendo "falsas", aquelas que são superimpostas aos indivíduos por interesses sociais particulares para reprimi-lo (as necessidades que perpetuam a labuta, a agressividade, a miséria e a injustiça). Pois, a sociedade industrial avançada nos propõe esforços e tendências para a consumação da racionalidade tecnológica dentro de suas instituições preestabelecidas, mostrando de forma clara seu aspecto contraditório, a perceptível contradição interna dessa civilização que nos leva a crer em necessidades falsas, fazendo com que o homem pense em ser livre, mesmo que na verdade não seja. $\mathrm{O}$ mesmo não consegue ter consciência de sua situação dentro da sociedade industrial avançada, nem mesmo de se opor contra esse aparato que continua dominando os indivíduos.

Os controles sociais se fundamentam nas necessidades irresistíveis da produção e do consumo de itens supérfluos, nos modos de relaxamento que aliviam e prolongam o processo de imbecilização da livre vontade de escolha entre, acessórios e marcas inúteis por meio da dominação de um todo repressivo que transforma, a liberdade em um instrumento poderoso de controle e dominação.

O padrão de pensamento e comportamento unidimensional surge de ideias, aspirações e objetivos que, transcendem o universo do discurso estabelecido e da ação. Repelidos ou reduzidos aos termos desse universo, eles acabam sendo redefinidos pela racionalidade do sistema em sua extensão quantitativa. Porque, o 
pensamento unidimensional é sistematicamente promovido pelos técnicos da política e seus dadores de informação de massa. Seu universo do discurso segundo Marcuse, é povoado por hipóteses que se autoavaliam e que torna-se definições hipnóticas.

Logo, a sociedade industrial se torna irracional quando o sucesso de seus esforços abrem novas dimensões para a realização humana, porém, em termos práticos, ela se organiza para uma dominação mais efetiva do homem e da natureza. Toda liberdade depende da conquista de necessidades e da realização de liberdade que depende das técnicas de conquistas, pois, a racionalidade tecnológica acaba revelando seu caráter político quando se torna um grande meio de dominação, criando um universo totalitário, com a perpetuação do trabalho. Organizado e dirigido pelo aparato produtivo que age como forma de controle dos indivíduos, dentro de sua racionalidade e padrão de pensamento e comportamento unidimensional.

\section{Referências}

FLORENNE, Y. L'homme unidimensionnel, de H. Marcuse. Le Monde Dipomatique. Paris, jun. 1968.

MARCUSE, H. O homem unidimensional: estudos da ideologia da sociedade industrial avançada. Tradução de Robespierre de Oliveira, Deborah Christiana Antunes e Rafael Cordeiro Silva. São Paulo: EDIPRO. 2015.

. A ideologia da sociedade industrial - O homem unidimensional. Tradução de Giasone Rebuá. Rio de Janeiro: Zahar Editores. 1982.

Submissão: 20.07.2017 / Aceite: 15. 11. 2017 